\title{
Smoking Impairs the Response to a Physical Training Regime: A Study of Officer Cadets
}

Maj N A Hoad

MA, MRCP, RAMC*

\section{Maj D N Clay \\ MSCP, APTC}

\section{Army Chest Unit and School of Physical Training, Aldershot}

SUMMARY: One hundred and sixty five officer cadets completed a 6 month physical training programme; $47(28 \%) \stackrel{\mathbb{\Phi}}{\circ}$ were smokers and $118(72 \%)$ were not. Improvements in fitness were measured by the Army Personal Fitness Assessment (APFA) which scores for both strength and endurance. Initially both groups had similar APFA scores [mean (SEM)]: smokers 114 (3.1), non smokers 120 (2.3), difference not significant. Six months later both groups had improved their scores: smokers $131(2.7)$, non smokers $143(2.3)$, but the smokers were now significantly less fit $(p<0.01)$. $\vec{\omega}$ The British Army needs a more effective anti smoking policy as $50 \%$ of young soldiers continue to smoke, and have an $\stackrel{\Omega}{S}$ increased risk of premature ischaemic heart disease when compared with their civilian counterparts. Physical fitness $\bar{\Omega}$ remains important in the Army and evidence such as this may help persuade soldiers to give up smoking before standard tests of cardiovascular or lung function show any abnormalities, with benefits for the future health of the Army.

\section{Introduction}

Smoking is the largest preventable cause of death in the United Kingdom $(1,2)$, but a recent survey has shown that $50 \%$ of young soldiers still smoke (3), a figure which has fallen little in the last 20 years $(4,5)$, against the national trend (6). Studies have shown that soldiers have an increased risk of premature ischaemic heart disease when compared with civilian contemporaries of similar socioeconomic status $(7,8)$ : the only differing risk factor is that soldiers smoke more heavily (9).

Attempts to persuade soldiers to stop smoking fail partly because these apparently fit young men do not believe that it is doing them any immediate harm, and are unwilling or unable to comprehend the long term consequences. Physical fitness remains important even in today's Army, where repeated failure in the Basic Fitness Test (BFT) eventually results in downgrading and loss of promotion prospects. Recent reports from the USA have suggested that servicemen who smoke are less fit that those who do not $(11,12,13)$. If these reports are true then we might more easily be able to persuade soldiers to stop, especially those who find the BFT difficult.

We extended the previous work by following a group of Army officer cadets through a six month training programme, and comparing the improvements in fitness of smokers and non smokers. Up to a third of soldiers who smoke start to do so during basic training (3), and if we could show that smokers cannot achieve a standard of fitness equal to non smokers then it may be easier to persuade them not to start at all.

\section{Method}

We studied 165 British Army officer cadets at the

*Now Consultant Chest Physician, British Military Hospital, RINTELN, BFPO 29
Royal Military Academy, Sandhurst (RMAS) who had $\stackrel{\omega}{\omega}$ just successfully completed their training. Forty-seven $(28 \%)$ had smoked throughout the course and $118(72 \%){ }_{0}^{N}$ had not. Each group was of similar mean age. All hag previously received joining instructions which includeg advice on the basic standard of fitness needed on arriva $\$$

At RMAS all cadets take part in standardised daif physical training which is well supervised and very cong petitive. It includes forced marching and running, wt th $\overrightarrow{0}$ and without equipment, assault courses, swimming ande circuit training. The intention is to achieve maximal i dividual improvement in both strength and endurance. monitored by regular use of the Army Personal Fitness Assessment (APFA), which gives a combined overall fitness score.

The strength test is in two sections. First the maximum number of repetitions of press ups, sit ups on an inclined $\overrightarrow{\vec{B}}$ board, pull ups to a horizontal beam and arm dips on parallel bars are counted and added together. There is no set time limit for each exercise, but no rests are allowed during any one exercise. The score is read from a table. $\exists$ Secondly the maximum height reached by the outstretched hand is measured from a standing jump. A correction is made for height and the score is again read from $a \vec{\Phi}$ table, and then added to that of the other exercises to give the total strength score.

Endurance is tested by the time taken on a 1.5 mile best effort run, with the score again being read from aio table. Both scores are combined to give the overall? APFA score. We compared the APFA scores of the smokers and non smokers at the beginning and end of their training programme by using Students $t$ test.

\section{Results}

Table 1 shows that APFA scores for the smokers and the non smokers, at the start and finish of their training. N Initially the smokers tended to be less fit, although not ${ }_{\sigma}^{\mathcal{G}}$ 
significantly so. After training both groups greatly increased their fitness but now the smokers were significantly less fit. Analysis of the scores for strength and endurance suggest that this difference is due to a lesser improvement in both elements of the APFA.

These results suggest that when subjected to the same physical training programme smokers are unable to become as fit as non smokers.

\begin{tabular}{|c|c|c|c|c|}
\hline & & $\begin{array}{c}\text { Table 1 } \\
\text { Smoker } \\
(47)\end{array}$ & $\begin{array}{l}\text { Non Smoker } \\
\text { (118) }\end{array}$ & Difference \\
\hline \multirow{2}{*}{$\begin{array}{l}\text { Overall } \\
\text { APFA Score }\end{array}$} & Pre & $114(3.1)$ & $120(2.4)$ & NS \\
\hline & Post & $131(2.7)$ & $143(2.3)$ & $\mathrm{p}<0.01$ \\
\hline \multirow{2}{*}{$\begin{array}{l}\text { Strength } \\
\text { APFA Score }\end{array}$} & Pre & $60(2.2)$ & $65(1.6)$ & NS \\
\hline & Post & $73(2.0)$ & $81(1.8)$ & $p<0.05$ \\
\hline \multirow{2}{*}{$\begin{array}{l}\text { Endurance* } \\
\text { APFA Score }\end{array}$} & Pre & $9: 41(: 06)$ & $9: 37(: 04)$ & NS \\
\hline & Post & $9: 21(: 05)$ & $9: 07(: 03)$ & $\mathrm{p}<0.02$ \\
\hline
\end{tabular}

* Endurance Score Converted back to Time for 1.5 Mile Run (Min:Sec).

All Results Expressed as Mean (SEM), Pre and Post 6 months Training.

\section{Discussion}

The idea behind this study originated from our experience with the cardiac rehabilitation course at the Queen Elizabeth Military Hospital (14). We knew that too many soldiers smoked, that the rate of ischaemic heart disease in the Army was too high, and that anti smoking advice, successful elsewhere, appeared to have failed. We did not know why it had failed, but the consequence is that $50 \%$ of young soldiers smoke, compared with $30 \%$ of the civilian male population $(3,6)$.

Soldiers on the course could and did give up smoking after their myocardial infarction (14), but told us that previously they had been unwilling or unable to understand the concept of stopping smoking when well, in order to avoid disease in the distant future. What would have encouraged some at least to have given up when apparently well was evidence that smoking had already done them harm.

How best to detect early smoking related damage is unclear. Basic lung function tests with their wide normal ranges are not very helpful unless repeated over a long period of time (10). Tests of small airway function are less readily available. Smoking damages cardiovascular as well as respiratory function, and an assessment of physical fitness, depending as it does on the efficiency of both systems, may be a better way.

In the context of this study the testing of physical fitness has an added advantage. Even in a high technology army it is considered very important, and many soldiers remain proud of their own fitness. If soldiers who smoke can be shown to be less fit than those who do not, then this may be the way to encourage them to stop.
Some American studies had already suggested this to be true, but their method had been to do simple fitness assessments on groups of servicemen, without prior knowledge of their expected state of fitness or their normal physical training regime $(11,12,13)$. We aimed to confirm and extend these findings by following smokers and non smokers through a standardised physical training programme and comparing improvements in fitness.

We kept this preliminary retrospective study as simple as possible. The instructors only asked one question did you smoke throughout the course - and appended the answers to the individual cadet's APFA performance analysis. No information on height or weight was available, but as the initial APFA scores were similar in both groups this should not have been a significant omission.

Is the APFA a reliable measure of physical fitness? The Army Physical Training Corps are convinced that it is, and in well motivated subjects improvements in APFA correlate highly with improvements in other indices such as maximal oxygen uptake achieved during a maximal exercise test, currently the gold standard.

Motivation is crucial in any test of physical fitness. We are aware that some good runners are content to jog around the BFT circuit just within their permitted time therefore to use that as a test of fitness would be absurdo We chose RMAS for our study because we were confie dent that motivation would not be a problem. It is a extremely competitive environment, and the cadets know that APFA scores will count towards overall assessment. Officer cadets also have a longer training course than other recruits and undergo a well plannef and supervised physical training programme. They know the standard of fitness expected on arrival and should therefore all start from a similar baseline. Basic training is when many young soldiers start to smoke, and we hoped to show that they were unable to achieve a similar standard of fitness as non smokers. If so then we may be able to dissuade more recruits from starting to smoke, a valuable primary preventitive measure.

The APFA as described above is a reliable indicator of overall fitness, testing as it does both strength and endurance. The results of serial APFAs show that the smokers and non smokers do start at a similar level of fitness, but after six months of training the smokers are significantly less fit. When the two components of the APFA are separated, it appears that smokers improve less in tests of strength as well as endurance. This has been previously noted, and has been taken as evidence that smokers are less well motivated than non smokers (13). In our population this is unlikely, and as the strength tests can involve several minutes of sustained $\underset{O}{D}$. exertion they must be testing cardiovascular and pulmonary efficiency as well as sheer power.

This was a preliminary retrospective study, and further work will need to be prospective and perhaps include measurements of oxygen uptake and carbox- 
yhaemoglobin. We have however shown that in this group of army officer cadets those who smoke cannot achieve the same standard of physical fitness as those who do not, implying that even by the age of twenty smoking has impaired health. For soldiers who need to be physically fit this evidence may be what is needed to help reduce smoking levels in the Army; for recruits this may encourage them not to start at all, with great potential benefits for the future health of the Army.

\section{Acknowledgements:}

We thank the Physical and Recreational Training staff at RMAS for their help with collecting the data for this study.

\section{REFERENCES}

1. Davis R M, SMith R. Addressing the most important preventible cause of death. Br Med J 1991; 303: 732-3.

2. Moхнам J. Doctors for tobacco law. British Thoracic Society News 1991; 7: 1 .

3. LODGE L H. Tri-service health questionnaire 1989. $J$ R Army Med Corps 1991; 137: 80-3.

4. Crowdy J P, Lewthwaite C J, Sowden R R. Smoking: the changing habits of male adolescents. A comparison of three generations of young soldiers. J R Army Med Corps 1975; 121: 126-31.

5. CROWDY J P, Sowden R R. Cigarette smoking and respiratory ill-health in the British Army. Lancet 1975; i: 1232-4.
6. Golding J F. Smoking. In Cox B, Ed. The health and lifestyle survey. London: Health Promotions Research Trust 1987: 97.

7. LYNCH P, OlEman B J. Mortality from coronary artery disease in the British Army compared witho the civilian population. $\mathrm{Br} \mathrm{Med} J 1981 ; 283$ : 405-7.

8. GRAY J. Mortality from ischaemic heart disease in the armed forces 1973-84. JR Med Corps $1987 ; 133:$ 106-12.

9. LYNCH P. Coronary risk profile of young soldiers with coronary artery disease. JR Army Med Corps 1985; 131: 38-41.

10. PRIDE N B. Development of ventilatory impairmento in COPD. In: Brewis R A L, Gibson G J and Geddes D M, Eds. Respiratory Medicine. London: Balliere Tindall, 1990: 476-7.

11. JENSEN R G. The effect of cigarette smoking on army physical readiness test performance of enlisted army medical personnel. Milit Med 1986; 151; 83-5.

12. Conway T L, Cronan T A. Smoking and physical fitness among navy shipboard men. Milit Med 1988;क्त 153: $589-94$.

13. Bahrke M S, Bain T S, Palard O F, Connors D F. Tobacco use and performance on the US Army physical fitness test. Milit Med 1988; 153: 229-35.

14. HOAD N A. Management after coronary artery by N pass surgery: a rehabilitation course induces응 lifestyle changes which may improve long term graft survival. J R Army Med Corps 1989; 135: 135-8. 